\title{
IS DESICCATION THE CAUSE OF THE POOR SURVIVAL RATE IN THE ACCLIMATIZATION OF MICROPROPAGATED PRUNUS CERASUS L.?
}

\author{
J.A. Marín and R. Gella \\ Servicio de Investigación Agraria \\ D.G.A. \\ Zaragoza, Spain
}

El Dr. Juan Antonio Marín Velázquez (jmarin@eead.csic.es) es investigador EEAD-CSIC.

\section{Abstract}

Desiccation has been pointed out as one of the main causes of poor survival in acclimatized plants. However, the study of a number of factors affecting desiccation questions it.

Stomatal structure and functioning as well as cuticular structure and transpiration were studied on different types of leaves from in vitro and acclimatized plants of a micropropagated cherry rootstock with a low survival rate during acclimatization. Stomata of leaves from in vitro grown plants were shown to close, and this closure was faster with acclimatization. Moreover, in vitro leaf stomata had a similar structure to that of acclimatized plant leaves, although guard cells were richer in both starch and chloroplasts. Cuticular structure of in vitro leaves was similar to that of acclimatized plant leaves, but thinner, what could explain the greater transpiration rate found. Water transport through in vitro plant roots was also studied showing an effective transport. Anatomical studies of the root stem zone revealed no discontinuities in the xylem vessels.

Changes in the leaf structure were observed with acclimatization. In vitro plant leaves had a shade-leaf structure with a small mesophyll cell density and one palisade cell layer. However, after acclimatization, these leaves showed sun-leaf characteristics as a higher cell density and a double palisade cell layer.

Structural and functional evidence presented here do not support the idea of desiccation as being the cause of poor survival in the process of acclimatization. This point agrees with the fact that survival rate raised from 15 to 85 per cent by changing the environmental conditions, and is further supported by the fact that death of micropropagated $P r u n u s \quad c e r$ a $s u s$ plants during acclimatization started 15 days after transfer to soil.

\section{Introduction}

To answer this question it is important to determine how water is lost in micropropagated plants. Different ways of water loss have been described: 1) Through the stomata. Leaf stomata of in vitro micropropagated plants have a defective functioning which cannot control stomatal transpiration (Brainerd and Fuchigami, 1981, 1982; Wardle et al., 1979). 2) Through the cuticle. Micropropagated plants show a modified cuticle with an excessive cuticular transpiration (Grout and Crisp, 1977; Sutter and Langhans, 1979, 1982; Wardle et al., 1983). 3) A poor water transport through the roots. Either a defective union of the vessels of the root-stem area or an anomalous structure of the vessels reduce the water transport which cannot replace the water lost by transpiration (Grout and Aston, 1977; Fabbri and Bartolini, 1985). 
Anatomical studies have also related desiccation with the modified anatomy of micropropagated plants (Brainerd et al., 1981; Donnelli and Vidaver, 1984; Fabbri et al., 1986; Wetzstein and Sommer, 1982) which show a shade-leaf structure and a different contents of epicuticular waxes (Grout and Aston, 1977, 1978; Sutter and Langhans, 1979). However, information is lacking on any possible histochemical differences and on how these parameters might change in the process of acclimatization, as well as how they may be related to water loss.

On the other hand, the fact that the death of plants during acclimatization started as late as 15 days after transfer to soil (Marin and Gella, 1987) even when they were kept under plastic, indicates that desiccation, as the cause of poor survival in acclimatization, needs further study. In this paper, we describe the study of the different factors affecting desiccation, as well as the morphology and histochemistry of leaf tissues in order to find out whether desiccation is or not the cause of the poor survival rate during the acclimatization of a micropropagated fruit tree rootstock.

\section{Material and methods}

2.1. Plant material. The cherry rootstock 'Masto de Montañana' ( $P \mathrm{r} u \mathrm{n} u \mathrm{~s} \overline{\mathrm{e}} \overline{\mathrm{r}} \overline{\mathrm{a}} \mathrm{s} \mathrm{u} \mathrm{s}$ L.) was micropropagated as described in Marín and Gella (1987). Leaves from in vitro grown shoots have been compared with leaves from the acclimatized plants. In an aclimatized plant, two months after transfer to soil, different leaf types are distinguished: Leaves grown under in vitro conditions, but persisting after acclimatization (acclimatized leaves); leaves induced during in vitro culture, but developed after transfer to soil which show intermediate characteristics (intermediate leaves); and leaves differenciated in the glasshouse (new leaves). In addition, these leaves were compared with leaves of one-year-old acclimatized plants grown outdoors (normal leaves).

2.2. Acclimatization. Micropropagated plants were transferred to a peat: perlitie $(1 \overline{:} 1 \overline{)}$ substrate either under closed environments (small plastic pots covered with inverted plastic bags or trays covered with small plastic tents), or on a large bench covered with a plastic tent gradually opened at increasing periods. Frequent watering was applied to the large bench while, in closed environments, plants were watered after transfer to soil and then kept unaltered.

2.3. Stomatal closure. Stomata of detached in vitro leaves, acclimatized leaves and new leaves were photographed under a microscope (abaxial side up) after exposure to 45 per cent relative humidity $(\mathrm{r} . \mathrm{h}$.$) at five minutes intervals for up to 20$ minutes. The stomatal apertures were measured on the enlarged figures. At least 20 stomata were measured at each sampling time in five fields choosen at random, but rejecting those with a major vein. The experiment was repeated with three leaves of each type taken from different plants.

2.4. Transpiration rate. Water loss was studied in detached in vitro leaves, accilimatize $\bar{d}$ leaves and new leaves exposed to 45 per cent r.h. Their weight was determined at intervals of five minutes during the first hour and then their dry weight was obtained. For in vitro and acclimatized leaves groups of ten leaves were used to reduce 
errors due to their small size. The experiment was repeated three times.

2.5. Water transport. Rooted plants with the roots dipped in a solution of fluoresceine sodium salt (Pimienta and Polito, 1982) were exposed to 45 per cent r.h. Plants were taken at different times and hand-made longitudinal sections were made to follow the progress of fluoresceine under a fluorescent microscope.

2.6. Anatomical and histochemical studies. Tissues from all leaf types wer $\bar{e} \bar{f} i \bar{x} e \bar{d}$ and $\bar{d}$ dehy $\bar{d} r \bar{a} t \bar{e} \bar{d}$, and then coated with a thin film of gold for the scanning electron microscope (SEM) studies, or embedded in JB4 resin (Polysciences Inc.). Sections of 1 um were cut and stained with the following stains to show different constituents: auramine O (Heslop-Harrison, 1977; Sheldon and Dickinson, 1983) for cutin, calcofluor (Hughes and McCully, 1975; Heslop-Harrison and Heslop-Harrison, 1981) for cellulose, ruthenium red (Gurr, 1965; Heslop-Harrison, 1979) for pectins, and the periodic acid-Schiff procedure (PAS) (Feder and O'Brien, 1968) for insoluble carbohydrates. Fresh epidermal (abaxial) strips were stained either with IKI solution (Johansen, 1940) for starch or aniline blue (Martin, 1959) for callose.

The root-stem zone of micropropagated plants was studied by hand-made longitudinal sections stained with phloroglucin-HCl (Jensen, 1962) to show lignin.

\section{Results}

3.1. Stomatal structure and functioning. Some differences were

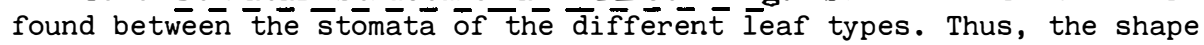
of in vitro stomata was round instead of the normal elliptical one showed in normal and acclimatized plants, which is responsible of the bigger apertures found in in vitro leaves. Differences were also found in the contents and distribution of both starch and chloroplasts, which were more abundant and placed along the guard cells in vitro leaves, while they were few and placed at the ends of the guard cells in the rest of the leaf types. However, these differences disappeared after acclimatization in persistent acclimatized leaves. In contrast, the histochemical studies showed no differences in the constituents of the cuticle of the different leaf types, including cutin, as an external layer, pectines, surrounding the lumen of the guard cell, and cellulose. Cellulose microfibrils showed the same (radial) arrangement in all leaf types, as seen under polarized ligth with the Red I plate, but the intensity of birefringence, smaller in in vitro leaf stomata, revealed quantitative differences which are related with differences in the thickness of the cell wall. In vitro leaf stomata had thinner cell walls than stomata from the rest of the leaf types. However, callose was stained in the interguard-cell wall of the leaves grown both in vitro and in the greenhouse, but not in the normal leaves grown outdoors.

Different behaviour was shown by stomata of detached in vitro, acclimatized and new leaves when exposed to low r.h. Thus, while stomata of new leaves, grown in the greenhouse, were closed at time 0 , only a 75 per cent of in vitro leaf-stomata were closed after 15 minutes. Persistent acclimatized leaves speeded up the process closing 
98 per cent of their stomata in that time (figure 1 ).

3.2. Cuticular structure and transpiration. All the different leaf

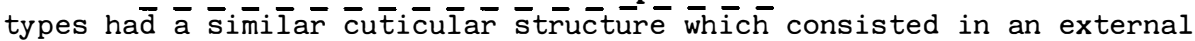
continuous layer of cutin subtended by a pectin layer with expansions towards the anticlinal cell walls, and cellulose which continued in the epidermal cell wall. SEM samples of all leaf types, except in vitro leaves, showed cuticular ridges on the adaxial surfaces, but not on the abaxial, where only the normal leaves grown outdoors did. Normal leaves showed a thicker cuticle in both the adaxial and the abaxial leaf surfaces as well. In vitro leaves, with a thinner cuticle, lacked well-defined cuticular ridges.

Water loss of detached in vitro leaves was greater than that of normal leaves (figure 2). Persistent acclimatized leaves showed an intermediate situation. When water loss was plotted against time it followed an exponential curve, then transpiration rates were calculated for the different leaf types. The rate of water loss in in vitro leaves was twice the rate of acclimatized leaves and four times the rate of new leaves. Water loss was very fast in in vitro leaves, being lost more than 95 per cent of leaf water content after one hour of exposure (figure 2). These transpiration rates may be related with the observed anatomical features.

3.3. The root-stem zone and water transport. No discontinuities in xylem vessels were observed when longitudinal sections of the root stem zone were stained for lignin. In addition, water transport (seen as the progress of fluorescein in the plant) was effective, reaching the root-stem zone in less than ten minutes, and the leaves in less than twenty minutes.

3.4. Leaf structure. There was an influence of the characteristics of the environment, in which leaves grew, on their structure. Shade-leaf structure was observed in transverse sections of in vitro leaves with large intercellular air spaces and a low mesophyll cell density, but with a differentiated palisade cell layer, while normal leaves grown outdoors showed a well defined sun-leaf structure with small intercellular air spaces, high cell density, and a double palisade cell layer. Greenhouse grown leaves (intermediate and new) showed a less pronounced shade-leaf structure with only one palisade cell layer. In constrast, acclimatized leaves, previously grown in vitro, had sun-leaf charactetistics with higher cell density and a double layer of palisade cells.

3.5. Acclimatization. While low survival rates (10-20 per cent) were obtained during acclimatization of micropropagated plants when maintained in closed environments, higher survival rates were obtained providing succesive exposures to low r.h., as well as frequent watering, raising the survival rate up to 86.4 per cent with a total of 2056 plants in different batches. The death of plants started 15 days after transfer to soil (figure 3 ), at the same time as in closed environments, and the process became stabilized in two weeks.

\section{Discussion}

In contrast with previous reports which explained poor survival 
rates in terms of desiccation (Sutter and Langhans, 1979; Brainerd and Fuchigami, 1981), the results shown here do not support this, since there was no relation between loss of water and death of plants. Thus, stomata of in vitro leaves were shown to close in a great percentage after a short period of time and water transport through the roots was effective. On the other hand, cuticular transpiration was a too fast process (more than 95 per cent of water loss in one hour) to be the cause of the death of plants, which started 15 days after transfer to soil. Furthermore, micropropagated plants were able to adapt to new conditions by modifying their anatomical structures, which did not show qualitative but quantitative differences in their constituents.

The non functional state of stomata of in vitro leaves, shown by the round shape and the abundance and distribution of both starch and chloroplasts, is reversible to a certain extent in a particular leaf, as in persistent acclimatized leaves, and completely reverts when new leaves differenciate in the new environment. The stomata of the different leaf types did not show important histochemical or structural differences, even in the radial arrangement of cellulose microfibrils which have an important role in the guard cell movements (Aylor et al., 1973; Raschke, 1975); only a less intense birefringence could be due, in in vitro leaves, to the thinner cell wall they have. Stomatal functioning followed a similar pattern. While stomata of new leaves showed an almost instantaneous closure, stomata from in vitro leaves took over 20 minutes to close. However this situation partly reverted since acclimatized leaf stomata closed faster than in vitro stomata, showing an adaptation of in vitro grown leaves to the new environment. Contradictory result have been reported on stomatal functioning. While stomatal closure as a response to low r.h. was found in cauliflower (Grout and Aston, 1977) and cabbage (Sutter and Langhans, 1982) only 20 per cent of closed stomata were found in apple (Brainerd and Fuchigami, 1981). These differences may be due to the method of measurement employed. The use of intact leaves, used here, has been recommended (Meidner, 1981) since this does not alter the interactions between stomata and the rest of the leaf.

While no differences were found in the constituents of the cuticle of the different leaf types, they showed a variable cuticular thickness, being thinner in in vitro leaves, what could be the cause of their greater water loss. Acclimatized leaves, grown in vitro, showed a smaller rate of water loss than in vitro leaves, revealing the adaptation to the new environment. The lack of a well developed layer of epicuticular wax in micropropagated plants was considered the main cause of desiccation (Sutter and Langhans, 1979; Grout and Aston, 1977) but this is not supported lastly (Sutter, 1985). Water loss probably occurred through the cuticle, since transpiration rates were independent of changes in stomatal aperture.

Some previous studies report a defective connection between root and stem in tissue cultured plants (Hughes et al., 1973; Aynsley and Marston, 1975; Grout and Aston, 1977) but this did not occur in the present work and there was an effective water transport between root and shoot. Roots, as a source of cytokinins, as well as nutrients and water (Torrey, 1976) might play an important role in acclimatization, and increasing watering during hardening could improve the water status of the roots and hence stimulate photosynthesis (Schulze, 1986).

Shade-leaf structure has been described in tissue cultured plants 
(Grout and Aston, 1978; Brainerd et al., 1981; Wetzstein and Sommer, 1982; Donnelly and Vidaver, 1984; Fabbri et al., 1986), being mainly a consequence of the low light intensity supplied. After transfer of plants to soil there is an increase in the light intensity which affects the structure of the leaves grown in vitro acquiring sun-leaf characteristics, increasing the cell density and doubling the palisade cell layer. However, leaves developed in the greenhouse showed some shade-leaf characteristics indicating that acclimatized leaves suffer a hyper-reaction to the environmental changes. This reaction has been described to a limited extent (Grout and Aston, 1978; Donnelly and Vidaver, 1984; Fabbri et al., 1986) as a certain elongation of palisade cells, but not the duplication of the palisade cell layer observed here. These differences could be a consequence of different sampling times. As mesophyll cell divisions last, at least, 23 days (Esau, 1977), they can only be observed after periods exceeding that time, as in the present work, where acclimatized leaves were observed two months after transfer to soil. The presence of callose could be considered as another shade-leaf characteristic of in vitro and greenhouse grown leaves, since callose has a role in the guard cell wall formation (Peterson et al., 1975). This is supported by the lack of callose in stomata of normal leaves grown outdoors.

The capability of in vitro leaves to react to a new environment, as well as the delay of the death after the transfer to soil, suggest that desiccation was not the main cause of the low survival rate. This is supported by the fact that survival was poorer in closed environments than in environments provided with increasing exposures to low r.h. and frequent watering. Since the ability to switch from an heterotrophic to an autotrophic state can be responsible for survival, an increase of transpiration and water transport, favoured in open environments, could positively affect the photosynthetic activity. A study on the photosynthetic ability of micropropagated plants and its evolution during acclimatization may give more indications of the causes of death of micropropagated plants.

\section{References}

Aylor, D.E., Parlange, J.Y. and Krikorian, A.D., 1973. Stomatal mechanics. Amer. J. Bot. 60: 163-71.

Aynsley, J.S. and Marston, M, 1975. Aerial plantlet formation in Asparagus officinalis L. Scientia Hortic. 3: 149-55.

Brainerd, K.E. and Fuchigami, L.H., 1981. Acclimatization of aseptically cultured apple plant to low relative humidity. J. Amer. Soc. Hort. Sci. 106: 515-8.

Brainerd, K.E. and Fuchigami, L.H., 1982. Stomatal functioning of aseptically cultured apple leaves. HortScience 17: 26.

Donnelly, D.J. and Vidaver, W.E., 1984. Leaf anatomy of red raspberry transferred from culture to soil. J. Amer. Soc. Hort. Sci. 109: $172-6$.

Esau, K., 1977. Anatomy of seed plants. Wiley and Sons. New York. 550 $\mathrm{pp}$.

Fabbri, A. and Bartolini, G., 1985. Osservazioni anatomiche su radichi di barbatelle di Paradox moltiplicate agamicamente. Frutticoltura 47: 43-6.

Fabbri, A., Sutter, E. and Dunston, S., 1986. Anatomical changes in persistent leaves of tissue-cultured strawberry plants after 
removal from culture. Scientia Hortic. 28: 331-7.

Feder, N. and O'Brien, T.P., 1968. Plant microtechnique: some principles and new methods. Amer. J. Bot. 55: 123-42.

Grout, B.W.W. and Aston, M.J., 1977. Transplanting of cauliflower plants regenerated from meristem culture. I. Water loss and water transfer related to changes in leaf wax and to xylem regeneration. Hort. Res. 17: 1-7.

Grout, B.W.W. and Aston, M.J., 1978. Modified leaf anatomy of cauliflower plantlets regenerated from meristem culture. Ann. Bot. 42: $993-5$.

Grout, B.W.W. and Crisp, P., 1977. Practical aspects of propagation of cauliflower by meristem culture. Acta Hort. 78: 289-96.

Gurr, E., 1965. The rational use of dyes in Biology. $422 \mathrm{pp}$. Leonard Hill. London.

Heslop-Harrison, J., 1979. Aspects of the structure, cytochemistry and germination of the pollen of rye (Secale cereale L.). Ann. Bot. 44, suppl. 1: 1-47.

Heslop-Harrison, Y., 1977. The pollen stigma interaction: pollen-tube penetration in Crocus. Ann. Bot. 41: 913-22.

Heslop-Harrison, Y. and Heslop-Harrison, J., 1981. The digestive glands of Pinguicola: structure and cytochemistry. Ann. Bot. 47: 293-319.

Hughes, H., Lam, S. and Janick, J., 1973. In vitro culture of Salpiglossis sinuata L. HortScience 8: 335-6.

Hughes, J., McCully, M.E., 1975. The use of an optical brightener in the study of plant structure. Stain Tech. 50: 319.

Jensen, W.A., 1962. Botanical Histochemistry. Principles and Practice. $407 \mathrm{pp}$. Freeman and Co., San Francisco.

Johansen, D.A., 1940. Plant Microtechnique. McGraw-Hill Book Co. New York. $523 \mathrm{pp}$.

Marin, J.A. and Gella, R., 1987. Acclimatization of the micropropagated cherry rootstock 'Masto de Montañana' (Prunus cerasus L.). Acta Hort. 212: Symposium "In vitro problems related to mass propagation of horticultural plants". Gembloux, 16-20 September 1985.

Martin, F.W., 1959. Staining and observing pollen tubes in the style by means of fluorescence. Stain Tech. 34: 125-8.

Meidner, H., 1981. Measurements of stomatal aperture and responses to stimuli, pp. 25-49. In Stomatal Physiology, eds. P.G. Jarvis and T.A. Mansfield, 295 pp. Society for Experimental Botany. Seminar Series, 8. Cambridge University Press. Cambridge.

Peterson, R.L., Firminger, M.S. and Dobrindt, L.A., 1975. Nature of the guard cell wall in leaf stomata of three Ophioglossum species. Can. J. Bot. 53: 1698-711.

Pimienta, E. and Polito, V.S., 1982. Ovule abortion in 'Nonpareil' almond (Prunus dulcis (Mill.) J.D.A. Webb). Amer. J. Bot. 69: 913-20.

Raschke, K., 1975. Stomatal action. Ann. Rev. Plant Physiol. 26: 309-40.

Schulze, E.D., 1986. Carbon dioxide and water vapor exchange in response to drought in the atmosphere and in the soil. Ann. Rev. Plant Physiol. 37: 247-74.

Sheldon, J.M. and Dickinson, H.G., 1983. Determination of patterning in the pollen wall of Lilium henryi. J. Cell Sci. 63: 191-208.

Sutter, E.G., 1985. Morphological, physical and chemical 
characteristics of epicuticular wax on ornamental plants regenerated in vitro. Ann. Bot. 55: 321-9.

Sutter, E.G. and Langhans, R.W., 1979. Epicuticular wax formation on carnation plantlets regenerated from shoot tip culture. J. Amer. Soc. Hort. Sci. 104: 493-6.

Sutter, E.G. and Langhans, R.W., 1982. Formation of epicuticular wax and its effect on water loss in cabbage plants regenerated from shoot-tip culture. Can. J. Bot. 60: 2896-902.

Torrey, J.G., 1976. Root hormones and plant growth. Ann. Rev. Plant Physiol. 27: 435-59.

Wardle, K., Dobbs, E.B. and Short, K.C., 1983. In vitro acclimatization of aseptically cultured plants to humidity. J. Amer. Soc. Hort. Sci. 108: 386-9.

Wardle, K., Quinlan, A. and Simpkins, I., 1979. Abscisic acid and the regulation of water loss in plantlets of Brassica oleracea L. var. botritis regenerated through apical meristem culture. Ann. Bot. 43: 745-52.

Wetzstein, H.Y. and Sommer, H.E., 1982. Leaf anatomy of tissue cultured Liquidambar styraciflua (Hamamelidaceae) during acclimatization. Amer. J. Bot. 69: 1579-86.

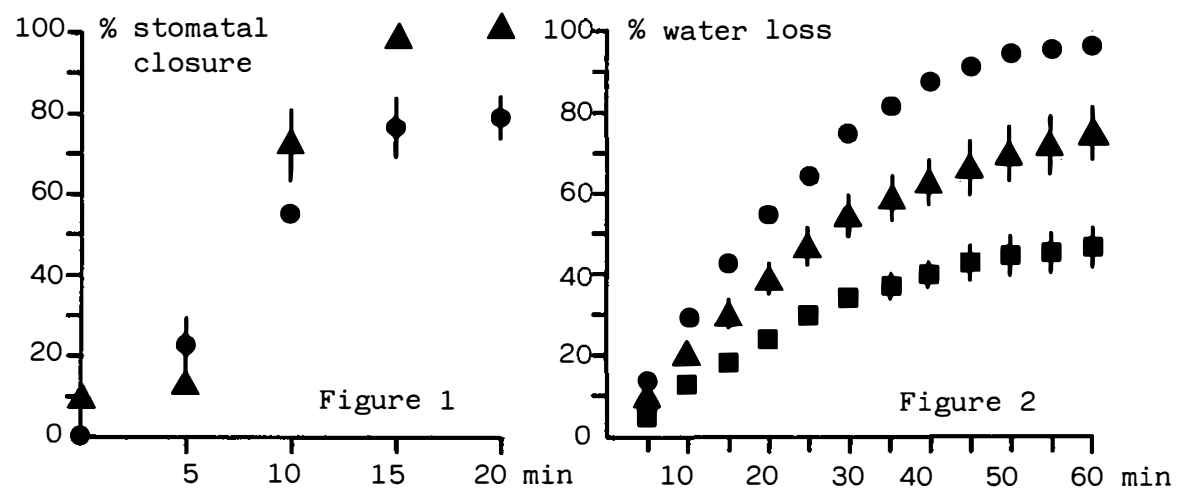

Figure 1. Stomatal closure of in vitro (৩) and acclimatized (A) leaves. New leaves had closed stomata at time $0(n=3$, bars $=s . e$.$) .$

Figure 2. Water loss of in vitro $(\boldsymbol{\bullet})$, acclimatized $(\boldsymbol{A})$ and new ( $\boldsymbol{\square})$ leaves as the percentage of leaf water content $(n=3$, bars $=$ s.e. $)$.

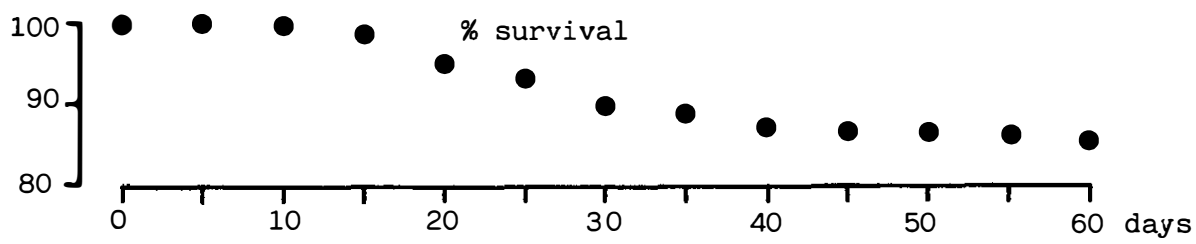

Figure 3. Survival percentage evolution in the acclimatization process (2056 plants). 